\title{
Toxoplasma seroepidemiology in women who intend to marry in Jahrom, Islamic Republic of Iran
}

M.H. Davami, ${ }^{1,3}$ M. Pourahamd, ${ }^{1,2}$ A.R. Sotoodeh Jahromi',3 and S.M.K. Tadayon ${ }^{4}$

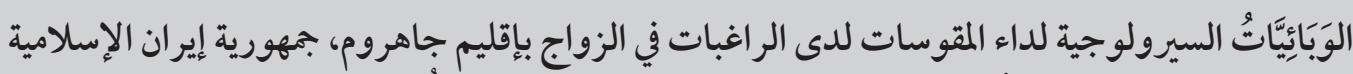

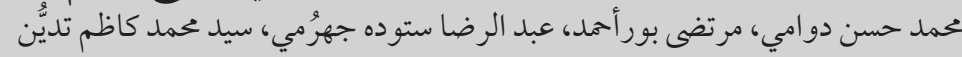

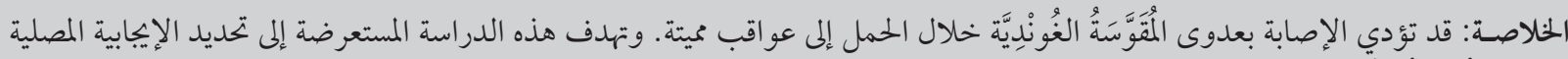

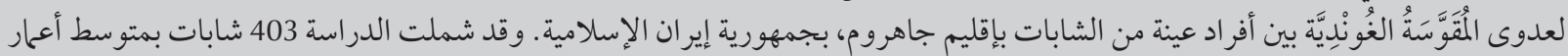

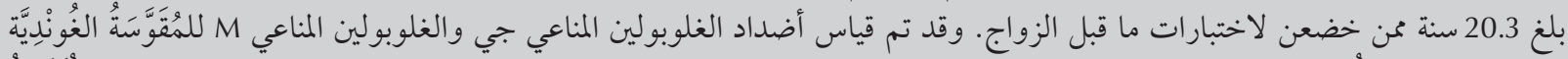

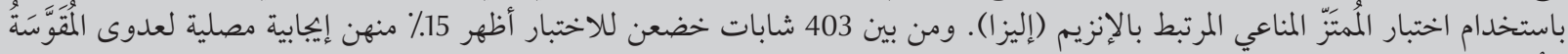

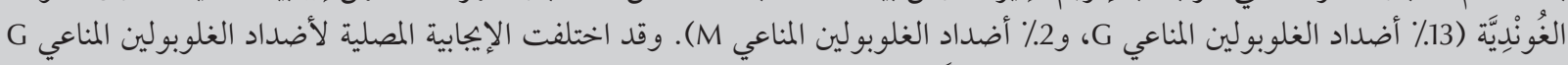

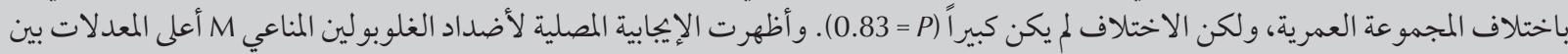

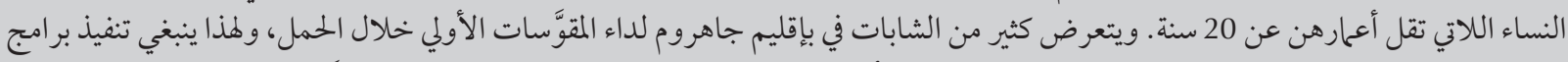

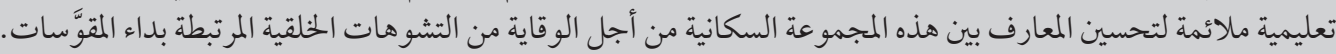

ABSTRACT Infection with Toxoplasmagondii during pregnancy can lead to severe fetal sequelae. This cross-sectional study aimed to determine T. gondii seropositivity among a sample of young women in Jahrom, Islamic Republic of Iran. Four hundred and three young women with a mean age of 20.3 years who presented for pre-marriage laboratory testing were entered in the study. T. gondii antibodies (IgG and IgM) were measured using ELISA. Of the 403 women, 15\% were seropositive for T. gondii antibodies (13\% for IgG and 2\% for IgM). Seropositivity for T. gondii $\lg$ differed according to age groups but there was no significant difference $(P=0.83)$. IgM seropositivity showed the highest rate among women aged $<20$ years. Many young women in Jahrom Province are susceptible to primary toxoplasmosis during pregnancy, therefore, appropriate educational programmes to improve knowledge in this population should be implemented to prevent toxoplasmosis-related congenital malformations.

Séroépidémiologie de la toxoplasmose chez des femmes ayant l'intention de se marier à Jahrom (République islamique d'Iran)

RÉSUMÉ L'infection par Toxoplasma gondii pendant la grossesse peut avoir de graves séquelles pour le fœetus. La présente étude transversale visait à déterminer la séropositivité à T. gondii dans un échantillon de jeunes femmes à Jahrom (République islamique d'Iran). Les 403 jeunes femmes, d'une moyenne d'âge de 20,3 ans, qui se sont présentées pour des examens biologiques prénuptiaux, ont été recrutées dans le cadre de l'étude. On a mesuré les anticorps anti-T. gondii (IgG et IgM) en utilisant la méthode ELISA. Sur les 403 femmes, $15 \%$ présentaient des anticorps anti-T. gondii (13\% pour les IgG et $2 \%$ pour les IgM). La séropositivité pour les IgG anti-T.gondii n'était pas identique selon les tranches d'âge, mais il n'y avait pas de différence significative $(p=0,83)$. Le taux de séropositivité le plus élevé pour les IgM a été observé chez les femmes de moins de vingt ans. De nombreuses jeunes femmes vivant dans la province de Jahrom ne sont pas immunisées contre la toxoplasmose primaire pendant la grossesse. II faut donc mettre en œuvre des programmes éducatifs appropriés afin d'améliorer les connaissances dans cette population pour les prévenir les malformations congénitales liées à la toxoplasmose.

${ }^{1}$ Department of Microbiology; ${ }^{2}$ Department of Internal Medicine; ${ }^{3}$ Zoonoses Research Centre; ${ }^{4}$ Department of Surgery, Jahrom University of Medical Sciences, Jahrom, Islamic Republic of Iran (Correspondence to M.Pourahamd: Mortezapourahmad@yahoo.com; Mortezapourahmad@) gmail.com).

Received: 09/03/12; accepted: 09/05/12 


\section{Introduction}

Toxoplasma gondii infection is a common global infection in humans and animals. The prevalence of toxoplasmosis varies between geographical areas depending on cultural and ecological factors [1]. The major reservoirs of this infection are cats, birds and domestic sheep and goats [2] and the main known route of transmission to humans is consumption of unclean vegetables, fruit and water, which can be contaminated with animal faeces, and consumption of raw or half-cooked meat [3].

Infection with $T$. gondii in patients with normal immunity usually improves without clinical symptoms, but infection in pregnant women may lead to premature delivery, congenital toxoplasmosis, and even fetal death [4-8]. In addition, some studies have shown that there is a suspicious relationship between prenatal depression and positive serology for toxoplasmosis in pregnant women [9].

The risk of transmission of this parasite to the fetus ranges from 0.6 to $1.7 \mathrm{per}$ 1000 pregnancies worldwide and it is estimated that congenital toxoplasmosis is the second most frequent intrauterine infection [10]. In the Islamic Republic of Iran, about 3200 children develop congenital toxoplasmosis every year [4].

Physicians should be aware of the risk of toxoplasmosis in pregnant women and the fetus. Therefore, it is important to know the immune status for this infection in women who want to become pregnant. To the best of our knowledge, there have been no previous reports about immune status of women in our region, and the susceptibility of mothers to deliver babies with congenital toxoplasmosis is unknown. We conducted this study in Jahrom, Southern Islamic Republic of Iran to determine the status of immunity to toxoplasmosis in young women who wanted to marry and were going to be pregnant in the near future. The results may be used in protocols for the prevention of congenital toxoplasmosis in the Islamic Republic of Iran.

\section{Methods}

We conducted this cross-sectional study on 403 young women who were tested for T. gondii antibodies (IgG and IgM) between April 2006 and March 2008 in Jahrom, Islamic Republic of Iran. The women had been referred to health centres for premarital laboratory tests, which are normally obligatory in the Islamic Republic of Iran. The women were selected by convenience sampling. The exclusion criteria were as follows: (1) women with autoimmune disorders; or (2) women with immunosuppression and/or malignancy. No additional needle administration was incurred by the women for the purposes of this study.

Informed consent was obtained and then blood samples were withdrawn. Then questions about age, residency, contact with cats, and type of meat consumption (boiled or roasted) were asked of each of the selected women. The Research Ethics Committee of the Jahrom University of Medical Sciences reviewed and approved the study design and the informed consent documents.

After blood sampling, serum was separated and kept at $-20^{\circ} \mathrm{C}$ until the enzyme-linked immunosorbent assay (ELISA) was performed. Serum IgG and IgM antibodies to $T$. gondii were measured using Toxo IgG and Toxo IgM ELISAs (Dia-Pro, Milan, Italy). Based on the manufacturer's guidelines, we considered IgG values $\geq 50 \mathrm{IU} / \mathrm{mL}$ to be seropositive and $<50 \mathrm{IU} / \mathrm{mL}$ to be seronegative. For IgM, the test was qualitative and the result was positive or negative.

All statistical analyses were performed using SPSS for Windows version 11.5. The frequencies and percentages were presented and the $\chi^{2}$ test was used for statistical evaluation. $P<$
0.05 was considered to be statistically significant.

\section{Results}

The characteristics of the pregnant women are listed in Table 1. The mean (SD) age of the 403 women was 20.35 (SD 4.77) years (range: $11-45$ years) Three hundred and five women (76\%) were aged $16-25$ years and 55 were $<16$ years.

Mean (SD) anti-toxoplasma IgG level was 102.16 (SD) $348.98 \mathrm{IU} / \mathrm{mL}$ (range: 0-3319 IU/mL) (Table 2). Of the 403 women studied, 52 (13\%) were positive for T.gondii $\operatorname{IgG}(\geq 50 \mathrm{IU} / \mathrm{mL})$ and $351(87 \%)$ were negative $(<50 \mathrm{IU} /$ $\mathrm{mL})$. Eight women $(2 \%)$ were positive and 395 (98\%) were negative for T. gondii IgM (Table 2). There was no significant difference regarding the presence of $\operatorname{IgG}$ antibody among different age groups $(P=0.83)$ (Table 2$)$. IgM seropositivity was highest in women aged $<20$ years, but the difference was not statistically significant $(P=0.27)$.

The frequency of $T$. gondii antibody (IgG and/or IgM) in rural residents was higher than in urban dwellers but the difference was not significant $(P$ $=0.53)($ Table 2).It should be noted that $66.3 \%$ and $45.8 \%$ of the rural and urban residents were below 20 years old, respectively. The frequency of total T. gondii antibody (IgG and IgM) in participants who had contact with cats (13\%) was not significantly different from that in those without contact (12.5\%) $(P=0.7)$. The frequency of $T$. gondii IgG and/or IgM in participants who used roasted meat (14.5\%) was not significantly different from that in those who used boiled meat (12.2\%) $(P=0.7)$.

\section{Discussion}

Eighty-five percent of the young women in our study were susceptible 


\begin{tabular}{|c|c|}
\hline Variable & No. (\%) \\
\hline \multicolumn{2}{|c|}{ Age group (years) } \\
\hline$<20$ & $191(47.4)$ \\
\hline $20-29$ & $195(48.4)$ \\
\hline$\geq 30$ & $17(4.2)$ \\
\hline \multicolumn{2}{|l|}{ Residence } \\
\hline Urban & $195(49.4)$ \\
\hline Rural & $200(50.6)$ \\
\hline \multicolumn{2}{|c|}{ Contact with cats } \\
\hline Yes & $391(980)$ \\
\hline No & $8(2.0)$ \\
\hline \multicolumn{2}{|c|}{ Type of meat } \\
\hline Roasted & $137(34.5)$ \\
\hline Boiled & $261(65.5)$ \\
\hline
\end{tabular}

to toxoplasmosis, which is similar to previous studies in the Islamic Republic of Iran $[3,4,11-14]$ and in other countries. In a study in Hebron, Palestine, $27.9 \%$ and $21.4 \%$ of rural and urban women, respectively, were positive for women were susceptible to primary toxoplasmosis during pregnancy [17]. In a prospective study in Italy, prenatal polymerase chain reaction showed that seven of 50 (14\%) had positive immunological status for toxoplasmosis, and $17 \%$ of their infants were infected at 1 year serological follow-up [18]. In a study in Shanghai, China to explore the prevention and treatment of early pregnancy TORCH infection (toxoplasmosis, other infections, rubella, cytomegalovirus, herpes simplex 2), $3.28 \%$ of cases were positive for Toxoplasma IgM antibody [19].

Therefore, we should pay particular attention to toxoplasmosis in young women in order to prevent complications of this disease during pregnancy. In our study, although the frequency of seropositivity differed between the age groups, the difference was not statistically significant. This pattern contradicts some other studies. For example, in a study in Goiania, Brazil, age 20-30

\begin{tabular}{|c|c|c|c|c|}
\hline \multirow[t]{3}{*}{ Variable } & \multicolumn{2}{|c|}{ IgG } & \multicolumn{2}{|c|}{ IgM } \\
\hline & Positive & Negative & Positive & Negative \\
\hline & No. (\%) & No. (\%) & No. (\%) & No. (\%) \\
\hline \multicolumn{5}{|c|}{ Age group (years) } \\
\hline$<20$ & 24 (12.6) & $167(87.4)$ & $6(3.1)$ & 185 (96.9) \\
\hline $20-29$ & $25(12.8)$ & $170(87.2)$ & $2(1.0)$ & 193 (99.0) \\
\hline$\geq 30$ & $3(17.6)$ & $14(82.4)$ & $0(0.0)$ & $17(100.0)$ \\
\hline Total & $52(12.9)$ & 351 (87.1) & $8(2.0)$ & 395 (98).0 \\
\hline$P$-value & \multicolumn{2}{|c|}{0.83} & \multicolumn{2}{|c|}{0.27} \\
\hline \multicolumn{5}{|l|}{ Residence } \\
\hline Urban & 23 (11.9) & $171(88.1)$ & $5(2.6)$ & $189(97.4)$ \\
\hline Rural & 29 (14.6) & $170(85.4)$ & $3(1.5)$ & $196(98.5)$ \\
\hline$P$-value & \multicolumn{2}{|c|}{0.53} & \multicolumn{2}{|c|}{0.72} \\
\hline \multicolumn{5}{|c|}{ Contact with cats } \\
\hline Yes & $51(13)$ & $340(87.0)$ & $8(2.0)$ & $383(98.0)$ \\
\hline No & $1(12.5)$ & $7(87.5)$ & $0(0.0)$ & $8(100.0)$ \\
\hline$P$-value & \multicolumn{2}{|c|}{0.72} & \multicolumn{2}{|c|}{0.8} \\
\hline \multicolumn{5}{|c|}{ Type of meat } \\
\hline Roasted & $20(14.6)$ & $117(85.4)$ & $2(1.5)$ & 135 (98.5) \\
\hline Boiled & $32(12.3)$ & $229(87.7)$ & $6(2.3)$ & $255(97.7)$ \\
\hline$P$-value & \multicolumn{2}{|c|}{0.74} & \multicolumn{2}{|c|}{0.84} \\
\hline
\end{tabular}


years was found to be a risk factor for toxoplasmosis [20]. We cannot draw similar conclusions because our study was not designed for that purpose and the proportion of women in each age group was not equal.

One of the recommendations for the prevention of congenital toxoplasmosis is educating women of reproductive age to avoid contact with soil (e.g. farming and gardening) [21]. Some authors suggest that health education for all pregnant women (especially focused on local risk factors) can reduce the incidence of congenital toxoplasmosis $[17,22]$. We found that the proportion of young women aged $<20$ years, and who intended to marry, was higher in rural than in urban areas (66.3\% vs. $45.8 \%)$. Therefore, more emphasis should be placed on health education in the rural population in the present study. In addition to educational programmes for rural residents, all general physicians and obstetricians should consider toxoplasmosis during pregnancy as a major health concern and provide appropriate recommendations for women at risk.

The presence of Toxoplasma-specific IgG does not always mean that an individual has absolute protection against infection. Therefore, regardless of immune status, hygienic and dietary preventive measures should be considered [23].

Toxoplasma transmission to the fetus nearly always happens during gestation or shortly before conception. Otherwise healthy women with previous toxoplasmosis only rarely transmit the infection to their infants. In some countries (such as France and Austria) seronegative pregnant women are tested monthly during gestation. In women who are positive for anti-Toxoplasma IgG, serum should be tested for IgM, followed by confirmatory testing if IgM is positive. In women with a positive titre for anti-Toxoplasma IgG, without clinical signs, and a negative IgM antibody test result in the first trimester, no further testing is necessary, because the probability of acute acquired infection is rare in such cases [24]. A negative IgM test rules out acute infection in the second trimester of pregnancy, but in the third trimester, a negative IgM result may occur with acquisition of infection earlier in gestation [25]. It is recommended to treat acute infection in the first trimester with spiramycin and in the second or third trimester by pyrimethamine-sulfadiazine [25].

In our study, $13 \%$ of the women had a history of contacts with cats, which is similar to studies in other countries such as Korea (13\%) [26] and Ireland (12.8\%) [27]. In some studies, such as that of Daryani and Sagha [3], contamination of meat is presented as the main route for toxoplasmosis transmission, which may be dependent on the method of preparation of the meat. In our study, the method of cooking was not significantly different in women with high or low titre of toxoplasmosis.

In conclusion, a high number of young women in Jahrom are susceptible to primary toxoplasmosis during pregnancy, therefore, appropriate educational programmes should be implemented to raise awareness of and prevent Toxoplasma-related congenital malformations.

Funding: The study was funded by Jahrom University of Medical Sciences, Jahrom, Islamic Republic of Iran.

Competing interests: None declared.

\section{References}

1. Dupouy-Camet J et al. Mode de contamination, incidence et prévalence de la toxoplasmose [Mode of transmission, incidence and prevalence of toxoplasmosis]. Médecineet Maladies Infectieuses, 1993, 23:139-147.

2. Hill D, Dubey JP. Toxoplasma gondii: transmission, diagnosis and prevention. Clinical Microbiology and Infection, 2002, 10:634-640.

3. Daryani A, Sagha M. [Toxoplasmosis seroepidemiology in girls who have come to Ardebil health city center for premarriage tests]. Journal of Ardabil University of Medical Sciences, 2004,4:19-25 [In Farsi].

4. Fallah E et al. [Epidemiologic evaluation of toxoplasma infection in high school girls of Jolfa]. Fertility and Infertility Seasonal Journal, 2005, 3(6):261-269 [In Farsi].

5. Villena I et al. Congenital toxoplasmosis in France in 2007: first results from a national surveillance system. Eurosurveillance, 2010,15(25):pii =19600.

6. Al-Hamod D et al. Delayed onset of severe neonatal toxoplasmosis. Journal of Perinatology, 2010, 30:231-232.

7. Anna A. [Toxoplasma, parvovirus and cytomegalovirus infections during pregnancy]. Duodecim, 2010, 126:159-166 [In Finnish].
8. Brkic $\mathrm{S}$ et al. [Seroprevalence of toxoplasmosis in Vojvodina]. Srpski Arhivza Celokupno Lekarstvo, 2010, 138:333-336 [In Serbian].

9. Groer MW et al. Prenatal depression and anxiety in Toxoplasma gondii-positive women. American Journal of Obstetrics and Gynecology, 2011, 204:433.e1-7.

10. Bojar I, Szymanska J. Environmental exposure of pregnant women to infection with Toxoplasma gondii - state of the art. Annals of Agricultural and Environmental Medicine, 2010, 17:209-214.

11. Mansoori $\mathrm{F}$ et al. [Seroepidemiology of toxoplasmosis in Kermanshah province (2000-2001)]. Behbood, 2003, 2:12-19 [In Farsi].

12. Talari SA et al. [Seroepidemiology of Toxoplasma gondiiin pregnant women referring to Ashrafi Esfahani Hospital in Khomeinyshahr during 1999-2001]. Feyz Journal of Kashan University of Medical Sciences, 2003, 24:32-37 [In Farsi].

13. Saeedi M, Veghari GR, Marjani A. Seroepidemiologic evaluation of anti-toxoplasma antibodies among women in north of Iran. Pakistan Journal of Biological Sciences, 2007, 10:2359-2362.

14. Saeidi M et al. [Seroepidemiology of antitoxoplasma antibodies in women who refered for marriage consultation]. Journal 
of Gorgan University of Medical Sciences, 2003, 9:64-71 [In Farsi].

15. Nijem KI, Al-Amleh S. Seroprevalence and associated risk factors of toxoplasmosis in pregnant women in Hebron district, Palestine. Eastern Mediterranean Health Journal, 2009, 15:1278-1284.

16. Akinbami AA et al. Seroprevalence of Toxoplasma gondii antibodies amongst pregnant women at the Lagos State University Teaching Hospital, Nigeria. Nigerian Postgraduate MedicalJournal, 2010, 17:164-167.

17. Ferguson $\mathrm{W}$ et al. Lack of awareness of risk factors for primary toxoplasmosis in pregnancy. Irish Journal of Medical Science, 2011, 180:807-811.

18. Di Carlo P et al. Investigation and management of Toxoplasma gondii infection in pregnancy and infancy: a prospective study. Acta Pharmacologica Sinica, 2011, 23:1063-1070.

19. $\mathrm{Fu} \mathrm{AH}$. [Pre-pregnancy and early clinical analysis of TORCH infections detection]. Zhonghua Shi Yan He Lin Chuang Bing Du XueZaZhi, 2009, 23:307-308 [In Chinese].

20. Sartori AL et al. Triagem pre-natal para toxoplasmose e fatores associados a soropositividade de gestantes em Goiania, Goias [Prenatal screening for toxoplasmosis and factors associated with seropositivity of pregnant women in Goiania,
Goias]. Revista Brasileira de Ginecologia e Obstetricia, 2011, 33:93-98.

21. Cvetkovic D et al. Risk factors for Toxoplasma infection in pregnant women in FYR of Macedonia. Parasite, 2010, 17:183-186.

22. Djurkovic-Djakovic O, Bobic B, Klun I. Toxoplasmosis in Serbia: time for an action plan. Parasite, 2010, 17:187-192.

23. Valdes $V$ et al. Toxoplasmose congénitale secondaire à une réinfection maternelle pendant la grossesse [Congenital toxoplasmosis due to maternal reinfection during pregnancy]. Archives de Pédiatrie, 2011, 18:761-763.

24. De Paschale M et al. Implementation of screening for Toxoplasma gondii infection in pregnancy. Journal of Clinical Medicine Research, 2010, 2:112-116.

25. Montoya JG, Kovacs JA, Remington JS. Toxoplasma gondii. In: Mandell GL, Bennett JE, Dolin R, eds. Mandell, Douglas, and Bennett's principles and practice of infectious diseases, 7th ed. Philadelphia, Elsevier/Churchill Livingstone, 2010:3370-3398.

26. Yang HJ et al. Seroprevalence of toxoplasmosis in the residents of Cheju Islan, Korea. Korean Journal of Parasitology, 2000, 38:9-13.

27. Taylor MR et al. Community study of toxoplasma antibodies in urban and rural schoolchildren aged 4-18 years. Archives of Diseases in Childhood, 1997, 77:406-409. 